\section{Free recall by retarded and nonretarded subjects as a function of input organization}

RICHARD L. SIMPSON, Olathe Unified Schools, Olathe, Kans. 66061, and JOHN D. KING and CLIFFORD J. DREW, The University of Texas at Austin, Austin, Tex. 78712

The free-recall performance of retarded and nonretarded $S$ s was compared as a function of two degrees of external input organization. $S$ classification interacted significantly with type of list. Results indicated that nonretarded $S s^{\prime}$ recall was not affected by the degree of external input organization. Retarded Ss recalled more items from the organized than from the unorganized lists. Fewer items were recalled by retarded than by nonretarded Ss under both list types.

Evidence concerning free-recall performance seems to indicate that retardates cluster items to a lesser degree than nonretarded Ss (Spitz, 1966). This phenomenon has given rise to the speculation that retardates exhibit a deficiency in the ability to organize or codify input in a manner that facilitates later response (Lipman, 1963; Rossi, 1963).

Gallagher (1969) criticized the methodological approach employed in studying input organization theory, noting that investigations have been generally limited to the associative clustering method. Gallagher states that the measurements of organization employed are dependent upon the E's knowledge of organization sources present in the material. This criticism seems to present a problem primarily when clustering performance is used as the dependent measure. In such cases, if differences are not evident, $E$ does not know if it is because clustering did not occur or because he has not identified the dimension upon which it did occur.

Gerjuoy \& Spitz (1966) seem to have circumvented this problem by using clustering as external input organization. By using clustering as an experimental variable, the appropriateness of the organizational dimension is immediately evident by its effect on a criterion measure. These investigators suggest that retardates are deficient in spontaneous organization but are capable of employing external organization to aid recall. They obtained results that support this line of reasoning and suggest the feasibility of facilitating retardate recall through external material organization. The purpose of the present study was to investigate the recall performance of retarded and nonretarded Ss as a function of external input organization.

\section{SUBJECTS}

Fifteen mentally retarded Ss were selected randomly from an institutional population with IQs ranging from 50 to 70 and CA 21 to 27 years. A nonretarded sample was similarly selected from a college-student population with CA 21 to 27. Ss evidencing a hearing, speech, chronic health, or behavior problem that might interfere with experimental performance were eliminated from the population prior to sampling procedures.

\section{MATERIALS}

Materials used in this study were 10 lists of five stimulus words equated for their mean log frequency of occurrence (Thorndike \& Lorge, 1944). Five of the lists were organized alphabetically and by conceptual category (trees, fruits, etc.). The remaining five lists were arranged in an unorganized fashion on the same dimensions. Stimulus terms used were only those that Ss could be assumed to be familiar with from pilot testing. Pilot test criterion for acceptable material consisted of use in context, definition, or explanation of each term by a retardate aged 24 and $1 Q$ of 50.

\section{PROCEDURE}

The Ss were individually tested in a room specifically assigned to avoid interruption. All testing took place during the hours of 8 to $11 \mathrm{a.m}$. and 1 to 4 p.m. Ss received standardized instructions and were given one practice trial to assure instruction comprehension. Words were then read aloud at a rate of $1 / \mathrm{sec}$. The last word in each list was followed by a $30-\mathrm{sec}$ free-recall period. Ss received one such recall trial on each of the 10 different word lists. The presentation of organized and within Ss to control for progressive error. RESULTS

Data were analyzed using a 2 by 2 (S Classifications by List Types) "mixed" analysis of variance with repeated measures (Winer, 1962). Number of correct responses served as the criterion measure. Table 1 summarizes mean correct responses by $S$ classification and list type. Results of

Table 1

Retarded and Nonretarded Mean Correct Responses by List Type

\begin{tabular}{lcc}
\hline \multirow{2}{*}{$\begin{array}{c}\text { Subject } \\
\text { Classification }\end{array}$} & Organized & Unorganized \\
\hline Retarded & 17.20 & 12.67 \\
Nonretarded & 24.00 & 23.73 \\
\hline
\end{tabular}
unorganized lists was counterbalanced the analysis indicated a significant interaction between both main effects variables $(F=28.80, p<.01, \mathrm{df}=1 / 28)$. This finding prompted further analysis using Tukey's Method a for testing differences between means (Winer, 1962).

Inspection of the means indicates that the significant interaction was obtained because of the differential effects on retarded and nonretarded Ss' performance by the type of list. Nonretardates' performance was not different as a function of material organization ( $p>.05)$. Retardates recalled significantly more items that were presented in an organized manner than those that were unorganized $(p<.01)$. Fewer items were recalled correctly by retarded than by nonretarded Ss under both list types $(\mathrm{p}<.01)$.

DISCUSSION
The present data do not speak to a short-term-memory comparison between $S$ classifications since there is no assurance of equal degrees of learning. Results of this investigation indicate that external organization of material influences the free recall of retardates to a relatively greater degree than nonretardates. The absence of a nonretardate performance difference as a function of list type suggests that external material organization may be of no consequence in immediate recall. This finding may, however, be in part a function of a ceiling effect.

Results of this investigation indicate that external input organization is a significant factor influencing the level of retardate recall. This finding is in agreement with the results of Gerjuoy \& Spitz (1966) and supports the hypothesis that the retardate is deficient in his ability to impose organization or codify material.

\section{REFERENCES}

GALLAGHER, J. R. A comparison of retarded and normals on subjective organization in short-term memory. American Journal of Mental Deficiency, 1969, 73, 661-665.

GERJUOY, I. R., \& SPITZ, H. H. Associative clustering in free recall: Intellectual and developmental variables. American Journal of Mental Deficiency, 1966, 70, 918-927.

LIPM A N, R. S. Le arning: Verbal, perceptual-motor, and classical conditioning In N. R. Ellis (Ed.), Handbook of mental deficiency. New York: McGraw-Hill, 1963. Pp. 391-423.

ROSSI, E. L. Associative clustering in organic and familial retardates. American Joumal of Mental Deficiency, 1963, 67, 691-699.

SPITZ, H. H. The role of input organization in the learning and memory of mental retardates. In N. R. Ellis (Ed.), International review of research in mental retardation. Vol. 2. New York: Academic Press, 1966. Pp. 29-56.

THORNDIKE, E. L., \& LORGE, I. The teacher's word book of 30,000 words. New York: Bureau of Publications, Teachers College, Columbia University, 1944.

WINER, B. J. Statistical principles in experimental design. New York: McGraw-Hill, 1962. 